\title{
Coping with the Unknown
}

\author{
Edited by \\ Sabine Mannitz and James Thompson
}

This special issue brings together research from various disciplines to not only assess the current state of human rights, aid and development projects, and legitimate governing orders - often framed as factors of human security - but also to critically examine the increasing reliance on measures of compliance and progress in these areas, reflecting the current "world of indicators," as Richard Rottenburg and Sally Engle Merry put it (2015). While the tools and models currently being utilized are indeed quite powerful, the call for different, more effective kinds of knowledge and evaluative instruments in the face of (allegedly increasing) uncertainty, nevertheless, continues to grow at the same time. Yet neither the various political or humanitarian crises, nor the urgent calls to take action are by any means new. Far from representing an unusual state of affairs, uncertainty is both fundamental to the human condition and the world we inhabit. John Dewey (1938) described the very contingency of social life as the starting point for human reflection, for the g eneration of $m$ eaning a nd s ocial constructions of evaluation.

What is characterized as uncertainty and contingency at the philosophical level is understood in terms of vulnerability and insecurity at the level of practical engagement and human interaction. Despite our best attempts to make our world certain, regular, thus predictable, we seem incapable of escaping this fundamental aspect of existence. Yet this apparently unbridgeable 'gap' is paired with another apparent constant, namely our undeterred efforts to make our world more certain and secure (even when these efforts themselves sometimes serve as further sources of insecurity). This understanding of the world and human practices represents one of the main tenets of pragmatist philosophy. Unlike more traditional and

Mannitz, Dr Sabine \& Thompson, Dr James: "Coping with the Unknown", Culture Unbound, Volume 13, issue 3, 2021. Published by Linköping University Electronic Press: http://www.cultureunbound.ep.liu.se 


\section{Culture Unbound}

historically dominant conceptions of knowledge, which presuppose a division between the theoretical and the practical, pragmatism conceives of epistemology in terms of our practical relationship to our environment and world. Expressed in terms of our topic, pragmatists are concerned with and focus on precisely the relationship humans have toward this 'gap', as well as the practices we employ and further develop to deal with these uncertainties. This inquiry intersects, in fact, with the ways in which social and cultural anthropologists, whose work is informed by practice theory - in the vein of Pierre Bourdieu, Sherry Ortner, and many others - understand and study human agency and the production of cultural and social meaning by "acting subjects" (Ortner).

Times of crisis inevitably provoke more pronounced responses, and the ongoing Covid crisis is no exception. The current pandemic highlights the continuing calls for action as well as amplifies the processes, strategies, and measures meant to address an even more uncertain, more fundamentally threatening future. The global nature of the Covid crisis has also laid bare the interwoven nature of several large-scale networks and their ambiguity. This level of integration and complexity is both a potential vulnerability and a strength of the contemporary world.

What was initially a healthcare crisis in one part of the world rapidly spread to other areas and transformed into a set of interlinking crises, the effects of which have acted as seismic waves disrupting entire economic systems, challenging social cohesion, and further aggravating the already growing political divides, economic and resource inequalities, bodily and financial security, and structural deficiencies with regards to, for example, healthcare and social services.

But these crises have also generated equally strong responses in the areas of communication, cooperation, and research to address these challenges and mitigate the effects of the pandemic - i.e., to regain a degree of control and make the crisis calculable. The calls for better infrastructure (both physical and digital), increased funding of hospitals and healthcare professionals, decreased reliance on certain countries or supply chains (i.e., greater diversity when it comes to critical infrastructure and key production facilities, such as pharmaceutical production and research facilities), and a more equitable allocation of resources have become much louder.

While the idea for this special issue originated well before the Covid crisis, and thus does not explicitly deal with it, the pandemic and its implications nevertheless serve to emphasize what we are trying to get at: how we deal with risk and uncertainty, and how these activities shape our relationship with the future. Alice Hills explores issues of security production by looking at how emergent police forces in two Somali cities, Kismayo and Baidoa, are shaped by cultural practices. Based on prototypical models of policing, political considerations, local power relations, and social phenomena have also served to shape the two police 


\section{Culture Unbound}

forces that find themselves within the general paradigm but at the other end of the technical and financial spectrum.

The adoption and adaption of circulating models to new environments and different situations is a tried-and-true means of creating a hoped-for future. The ethnographic investigation by Christina Garsten and Adrienne Sörbom looks at what they term "future industry," which is primarily engaged in the outlining and analysis of possible geopolitical scenarios. What has long been the domain of governments, institutions like think tanks, consultants, and some governmental bodies have made an industry out of organizing the future - and its alleged plannability. By taking a leading role in the process of anticipation, this industry's versions of the future are not only sketched out but also commented on and made into a commodity.

That the future industry is having a profound impact on how governments, private business, and citizens perceive and act toward their collective futures is made tangible by Astrid Matejcek and Julia Verne. In their contribution, they examine how the Tanzanian government is using specific technologies as a way to address and manage problems like climate change, rapid population growth, or conflicts related to land use and competing modes of livelihoods. While the use of the Mobile Application to Secure Tenure (MAST) by the government aims at making the agricultural futures in the Kilombero Valley actionable, it is also generating new insecurities and new economics of knowledge in this part of rural Tanzania, rendering it a double-edged sword.

And while technology and sophisticated theoretical modeling appear to be the dominant approaches to dealing with uncertainty and the future in this day and age, Annika Witte, with her ethnographic study in Uganda, shows us that we should not underestimate the effectiveness of perhaps the most common and informal forms of interpersonal communication: rumors and gossip. She explores how the discovery of oil there not only attracted companies and a mostly non-local workforce to the region, but it also opened up a space for rumors about the future of oil in the region and those involved in the oil business. In the absence of information from the government about the actual plans for developing oil, gossip and rumors spread throughout the local population and fueled - in a double sense - projections of the future. More than just 'talk' with a questionable factual basis, this practice can be seen as an exchange of risk narratives meant to share a possible dark future informed by past negative experiences.

Following up on the importance of lived futures, Johannes Schick offers a more theoretical reflection on futures and the role of technology in their production. Discussing the work of Henri Bergson and Gilbert Simondon, he points out that the increased technological development of prediction and control does not take into account the temporal dimension and anticipatory faculty of 


\section{Culture Unbound}

Journal of Current Cultural Research

living beings. Images play a key role in our structuring practices, and it is argued that the positive force attributed to them by Bergson can potentially be turned against itself when confronted with the numerous challenges currently facing humanity. Instead, human beings and the environment need to be conceived in terms of a constant and open-ended reinvention process.

While the modes of producing and measuring anticipatory knowledge that are discussed in this special issue imply the travel and transformation of ideas and/or norms, much more is at stake here: Without a theoretically guided understanding of human engagement with the world, of how social practices function, or even of the process of thinking, we are setting ourselves up for a fall back into overly simplistic understandings of the phenomena at play. Thus, it would seem critical that we approach the practices of measuring and producing (in)security both in terms of a nexus of social identity, organization, and interaction and as a site where thinking takes place, knowledge is (re)produced, and the power of decision-making is reconstituted in the carrying out of said practices. This means not only assessing the kinds of knowledge (and their corresponding tools) already at work, but equally important, looking to social practices in order to understand how these kinds of knowledge are produced in the first place. To this end, the contributions to this special issue are focused on and explore social facts, entanglements, and interfaces where anticipatory knowledge is actually generated and where it renders real consequences. At the same time, they demonstrate the potential of the particular interdisciplinary encounter of empirical anthropological research and pragmatist philosophical epistemology.

\section{References}

Bourdieu, Pierre 1977. Outline of a Theory of Practice. Cambridge \& New York: Cambridge University Press

Dewey, John 1938. Logic: The Theory of Inquiry. New York: Henry Holt.

Ortner, Sherry B. 2006. Anthropology and Social Theory: Culture, Power, and the Acting Subject. Durham: Duke University Press.

Rottenburg, Richard/Engle Merry, Sally/Park, Sung-Joon/Mugler, Johanna 2015 (eds). The World of Indicators: The Making of Governmental Knowledge through Quantification. Cambridge \& New York: Cambridge University Press. 